\title{
Curso «Introducción al arte rupestre prehistórico de la Península Ibérica», Ávila, 9-12 de julio de 1991
}

\author{
M. a Isabel Martinez Perelló
}

Durante el mes de julio de 1991 tuvieron lugar en Ávila los Cursos de Verano, organizados por diferentes Facultades y Departamentos de la UNED a través de su Vicerrectorado de Extensión Universitaria. Uno de los que obtuvieron mejor acogida por parte del alumnado fue el titulado Introducción al arte rupestre prehistórico de la Peninsula Ibérica, organizado por el Departamento de Prehistoria e Historia Antigua y dirigido por el doctor don Eduardo Ripoll. Tanto por el interés que suscitó el tema como por lo selecto del profesorado encargado de impartir las clases, que ya auguraba la calidad del mismo, se inscribieron un total de casi 200 alumnos. Un breve coloquio siguió a cada exposición, participando en el mismo cursillistas y profesores.

Comenzó el curso con la exposición del doctor don Joaquin González Echegaray, del Instituto de Investigaciones Prehistóricas de Santander, que versó sobre Paleoambientes de la cornisa cantábrica y su relación con el desarrollo del arte del Paleolitico Superior (cf. este mismo vol., págs. 73-86). En ella subrayó la importancia que posee el clima en la datación del arte rupestre, pues permite considerar - por derrumbes, anegación de galerias, formación de depósitos, etc.- conjuntos cerrados. Asimismo insistió en la importancia de la fauna representada como reflejo de un paleoambiente determinado y de un biotopo concreto, más decisivo incluso que los restos faunisticos recuperados en la excavación. Finalmente realizó un repaso de las principales cuevas con arte rupestre paleolítico del Norte de la Península Ibérica, estableciendo una serie cronológica y una datación tomando como base la representación de fauna que en ellas se plasma.

A continuación el doctor don Leslie G. Freeman, de la Universidad de Chicago, presentó con el título Seres, signos y sueños: la interpretación del arte paleolitico (cf. este mismo vol., págs. 87-106) un apasionante y apasionado recorrido por algunos de los motivos y paneles artísticos más 
interesantes de Altamira, presentando nuevas interpretaciones y defendiendo la existencia de un orden compositivo y de una estructura simbólica subyacente a un programa artístico, que seria común tanto a la galeria de la Cola de Caballo como al Gran Techo y que relacionaria al hombre con su entorno.

Altamira fue también el objetivo de la clase impartida por el doctor don Federico Bernaldo de Quirós, de la Universidad de León, Cuestiones en torno al arte de Altamira. En ella ofreció una interesante lectura de las pinturas desde el punto de vista del artista, siguiendo los trabajos de la doctora Muzquiz, y exponiendo el proceso de realización de éstas. Finalizó mostrando algunos de los motivos menos conocidos plasmados en Altamira y proponiendo sugestivas interpretaciones.

En su segunda jornada, el curso se inició con la lección El arte rupestre postpaleolítico y su facies levantina, impartida por el doctor don Eduardo Ripoll, de la UNED. Comenzó remontándose a la historia del descubrimiento del arte levantino y de su investigación, documentando la exposición con una amplia selección gráfica de conjuntos rupestres levantinos sumamente interesante y presentando la problemática de esta facies y su encuadre respecto a las demás del arte postpaleolítico peninsular.

Seguidamente, la conferencia del doctor don Mauro S. Hernández Pérez, de la Universidad de Alicante, El arte rupestre de la región central del Mediterraneo español ofreció a los cursillistas una completa visión de las manifestaciones artísticas localizadas en los últimos años en la zona meridional de Valencia, Albacete y Murcia. Comenzó con el arte rupestre paleolítico de Cova Reinos y Cova Fosca y el arte lineal-geométrico, asociado como arte mueble al Epipaleolítico Geométrico sin cerámica cardial. A los primeros grupos neoliticos adjudicó un nuevo tipo de pinturas rupestres, que por paralelos muebles - cerámica cardial e impresa de Cova del'Or - sitúa en el v milenio a. C., y que denomina «arte macroesquemático". A éste se superpone en algunas estaciones rupestres el llamado arte levantino, fechado por el profesor Hernández Pérez entre el $\vee$ y IV milenio a. C. También a partir del Neolítico Antiguo existiría otro tipo de arte rupestre totalmente diferente y que conviviria con el anterior: el arte esquemático. Este se desarrollaria durante el Neolítico Medio y Final y experimentaría su apogeo en el Calcolítico, con la incorporación de nuevos temas a su repertorio.

La jornada finalizó con la conferencia de la doctora doña Ana M. Muñoz Amilibia, de la UNED, Las innovaciones del Eneolitico y de la Edad del Bronce en relación con el arte rupestre. En ella repasó los cambios producidos en el iv milenio a nivel económico, industrial, de organización 
social y funerario ritual, con la expansión lenta y paulatina del Neolítico y la vinculación de los grupos humanos a un territorio muy concreto, siendo el megalitismo el fenómeno que mejor reflejará la cohesión del grupo y su vinculación a la tierra. La profesora Muñoz Amilibia adjudica el origen del arte levantino a los grupos cazadores-recolectores epipaleoliticos que van incorporando elementos neoliticos, mientras que el arte macroesquemático y esquemático pertenece a grupos ya neoliticos, de mentalidades muy diferentes.

El tercer día del curso se concibió como una clase práctica sobre arte rupestre, realizándose una excursión a Soria. Bajo la eficaz guia de su mejor conocedor, el doctor don Juan Antonio Gómez Barrera, se examinaron algunos de los bellos abrigos pintados del parque del Valonsadero y posteriormente se visitaron las ruinas de Numancia y el Museo Arqueológico de Soria.

El cuarto y último día del curso estuvo a cargo, en primer lugar, de la doctora doña Pilar Acosta, de la Universidad de Sevilla. Su conferencia La facies esquemática del arte rupestre postpaleolítico de la Peninsula Ibérica comenzó aportando algunos rasgos generales del arte esquemático, resaltando la importancia de la contextualización cultural enmarcada en el tiempo y en el espacio, para lo que se deben tener en cuenta los paralelos muebles y todos los restos materiales obtenidos en excavaciones y prospecciones. Estos han permitido situar el apogeo del arte esquemático en el Calcolítico Pleno, en el que aparece un código icónico ya formado y se multiplican tipos y tipologias que serán asimiladas de distinto modo por zonas y subáreas. La profesora Acosta ofreció finalmente a los cursillistas una amplia documentación gráfica en la que se apoyó para mostrar su aproximación a la descodificación de algunos motivos y conjuntos esquemáticos, cuya atractiva exposición se sumó a lo interesante de sus conclusiones.

En segundo lugar habló el doctor don Juan Antonio Gómez Barrera, acerca de Manifestaciones de la facies esquemática en el centro y norte de la Peninsula lbérica (cf. este mismo vol., págs. 231-264). Introdujo a los alumnos en el fenómeno esquemático de la pintura y el grabado rupestre localizado en el territorio de la Meseta norte, con los núcleos de las Batuecas, Duratón y Valonsadero para la pintura y las Hurdes, Soria, Segovia y Burgos para el grabado. Abordó los temas de la ubicación del arte rupestre y la probable sacralización de su emplazamiento en determinados casos, los problemas que ofrece su conservación y la descripción e interpretación de los conjuntos artísticos tratados. De este modo ofreció una visión amplia pero muy completa del arte postpaleolítico en la Meseta norte, colofón a la visita realizada el dia anterior al Valonsa- 
dero, donde se pudieron contemplar in situ algunos de los abrigos con pinturas rupestres analizados por el profesor Gómez Barrera en esta conferencia.

Para finalizar el curso, el doctor don Eduardo Ripoll discurrió sobre las Perspectivas de futuro en la investigación del arte rupestre prehistórico español, enmarcando el arte rupestre postpaleolítico peninsular como algo autóctono pero influido en ocasiones por unas corrientes culturales extrapeninsulares y ofreciendo un rápido pero significativo recorrido por el arte rupestre mundial -Europa, África, Asia, Australia y Sudamérica- que tantas veces permanece sin estudiar y en cuyo conocimiento tan poco han participado los estudiosos españoles, animando al auditorio a seguir esta línea de investigación. Finalizó su exposición con una breve mención a algunos temas fundamentales en el arte rupestre y cuya evolución y desarrollo ofrecen un campo de estudio atractivo e interesante, como, por ejemplo, el fuego, el agua y el arco.

El curso así se dio por clausurado, no sin que antes el doctor Ripoll agradeciese a los cursillistas su presencia, por corresponderles en gran medida el éxito de este primer curso sobre arte rupestre celebrado por la UNED, que esperamos siente precedente para años próximos dada la magnifica experiencia que ha supuesto tanto para alumnos como profesores.

Además del que nos ha ocupado, muchos otros cursos se llevaron a cabo en tres etapas durante el mes de julio de 1991 bajo la eficaz coordinación del doctor Blas Casado. Todos ellos tuvieron como escenario la magnífica sede denominada "Centros Universitarios" en la periferia de Ávila y con magnificas vistas sobre las murallas de la ciudad. El vicerrectorado de Extensión Universitaria de la UNED y la «Fundación Cultural Santa Teresa", con la ayuda de las Cajas de Ahorros Confederadas, han prolongado así, de forma muy efectiva, las tareas de enseñanza universitaria que les son propias. 